\title{
SINTAKSIČKI ASPEKTI KANONIČKIH I NEKANONIČKIH SLOŽENICA U ENGLESKOM I FRANCUSKOM DISKURSU ELEKTROTEHNIKE
}

\section{Sažetak}

U ovom radu se bavimo kanoničkim i nekanoničkim engleskim i francuskim složenicama iz perspektive sintaksičkih obeležja karakterističnih za ove jezičke fenomene. U prvom delu navodim radne definicije složenica koje su poslužile kao polazna tačka u istraživanju, kao i konstatacije koje se iznose u relevantnoj engleskoj i francuskoj lingvističkoj literaturi o složenicama. U drugom delu opisujem korpus koji je poslužio kao izvor podataka za argumente, zapažanja i zaključke koje iznosim u radu. U trećem delu utvrđujem relevantne kriterijume za selekciju engleskih i francuskih kanoničkih i nekanoničkih složenica. Četvrti deo predstavlja analizu sintaksičkih obeležja engleskih i francuskih složenica, a obuhvata: konstituentsku analizu, kombinovanje konstituenata složenica, nemogućnost sintaksičke interpolacije kao osobenost složenica, centriranost složenica u engleskom i francuskom jeziku kao sintaksičko obeležje složenica, sintaksičku rekurzivnost kao dominantno obeležje složenica. U petom delu rada iznose se zaključne napomene.

Ključne reči: kanoničke složenice, nekanoničke složenice, sintaksička obeležja, engleske složenice, francuske složenice, diskurs elektrotehnike.

\section{Uvodna razmatranja}

Prilikom proučavanja jezika struke u drugoj polovini XX veka, lingvistička pažnja je uglavnom bila fokusirana na rečenicu, a dalji razvoj lingvistike i jezika struke doveo je do pomeranja interesovanja sa rečeničnog nivoa na diskurs (Lakić 1999: 28). Naša pažnja u ovom 
istraživanju usmerena je na lingvističke segmente koji se u literaturi nazivaju pisani diskurs i govorni diskurs (Lakić 1999: 6) ${ }^{1}$.

U okviru ovog rada vršiće se ispitivanje na nivou diskursa i biće usmereno na jezički segment koji se naziva složenica. Razlog zašto smo za predmet našeg rada izabrali upravo složenice leži u činjenici da su ove jezičke jedinice učestale i statistički značajne u engleskom i francuskom diskursu elektrotehnike, ali da nisu detaljno analizirane na materijalu elektrotehničkog diskursa na jedan obuhvatniji način ${ }^{2}$.

Tokom istraživanja, utvrdio sam kriterijume za kanoničke i nekanoničke složenice koje opisujem i objašnjavam. Po svojoj orijentaciji, ovaj rad je deskriptivnog karaktera ${ }^{3}$, a nastoji da klasifikuje engleske i francuske složenice u diskursu elektrotehnike prema utvrđenim kriterijumima, kao i da analizira izvesna sintaksička obeležja kanoničkih i nekanoničkih složenica na materijalu ovog diskursa.

Pojedini engleski autori definišu složenicu kao reč, u smislu lekseme, koja se sastoji od druge dve reči (Bauer 1998: 65). Pored ovako uskih određenja, postoje i šira određenja složenice kod engleskih autora koji složenice definišu kao semantičke jedinice koje se sastoje od dve ili više komponenti ili reči (Aitchison 2001: 60). U obzir sam uzeo jedno prilično široko određenje složenice, kao svojevrsnu radnu definiciju i polaznu tačku u istraživanju, u okviru koga se složenica definiše kao reč koja se sastoji od dve ili više reči (Fabb 1998: 66). Pošto su imeničke složenice statistički relevantne u uzorku iz mog korpusa, kao radnu definiciju imeničkih složenica preuzimam određenje iz reprezentativne literature, u kojoj se imenička

$1 \quad$ Zbog prostorne ograničenosti rada, ovde se nećemo baviti terminološkim problemima i delimitacijom opozicije „pisani diskurs - govorni diskurs“ (za ovaj potonji termin koristimo još i naziv usmeni diskurs), već upućujemo na studiju Igora Lakića (1999) koja koncizno i precizno definiše ove lingvističke pojmove.

2 Međutim, lingvistkinja Jelena Vujić analizira bipolarne imeničke složenice u kompjuterskom registru iz morfološke perspektive (Vujić 2004: 155-166) i obrađuje složenice kao termine kompjuterskog registra sistematski, na više nivoa i na osnovu više različitih kriterijuma (Jelić-Vujić 2007: 175-180). Ljerka Bartolić se bavi interpretacijom složenica u tehničkom diskursu, posebno u elektrotehnici, fokusirajući se na raskorak sintakse engleskog i hrvatskog jezika (Bartolić 1979: 47-58), a Ana Fišer-Popović semantički analizira osobine imeničkih složenica u diskursu tehničkih nauka (Fišer-Popović 1981: 160-167). Kao što se to konstatuje u lingvističkoj literaturi, iako je deskriptivni pristup danas, uslovno rečeno, manje popularan, njegovom primenom može se doći do preciznih podataka koji mogu biti solidna polazna tačka za teorijska uopštavanja u okviru, možda primamljivijih, jezičkih teorija (Korać 1988: 11). 
složenica određuje kao jedinica interne strukture koja se može sastojati od sleda imenica, prideva i imenice, itd, ali čije sintaksičko ponašanje odgovara ponašanju proste imenice (Smith and Wilson 1979: 279).

Ovde vredi pomenuti da se u relevantnoj literaturi, kada se razmatraju razlike i sličnosti između reči $\left(X^{0}\right)$ i fraza $(X P)$, navodi da složenice ispoljavaju kako X ${ }^{0}$ svojstva, tako i XP svojstva (Di Sciullo 1997: 120). S jedne strane, prema fonološkim kriterijumima, složenice su $X^{0}$ pošto imaju jedinstveni naglasak na modifikatoru ${ }^{4}$, a prema konceptualnim kriterijumima one ispoljavaju konceptualnu i referencijalnu neprozirnost, dok su prema sintaksičkim kriterijumima, složenice neodvojive (Di Sciullo 1997: 120). S druge strane, prema kategorijalnim kriterijumima, složenice su XP, pošto obuhvataju više od jedne kategorijalne jedinice, mogu obuhvatiti $i$ frazni konstituent, a mogu ispoljavati pseudo-modifikaciju i pseudo-komplementaciju (Di Sciullo 1997: 120).

Francuski autori konstatuju da složenice nisu jedan kompaktan i homogen fenomen, koji bi se objasnio pomoću jedinstvene definicije (Gross 1990: 89), a ističu da složenice naročito mogu postati kompleksne u tehničkim oblastima (Gross 1986: 4). Postoje izvesni autori koji smatraju da prilikom definisanja složenica nije dovoljna striktno formalna definicija, ali ipak uzimaju u obzir sintaksičke testove za razlikovanje složenica od slobodnih sledova reči (Silberztein 1990: 72). U francuskoj literaturi, kada se govori o nekanoničkim, odnosno višečlanim složenicama, kaže se da se one naročito javljaju u tehničkom diskursu, a pošto se konstatuje da je teško razlikovati da li su onda takve jedinice sledovi reči, leksikalizovani sledovi, da li su proizvoljno generisani ili pak stabilni, francuski autori navode relevantan kriterijum za njihovu delimitaciju, a to je frekvencija upotrebe ovakvih leksičkih jedinica (Marcellesi 1977: 195). Savremeni francuski autori obrađuju i konstrukte koji se prema ranijim klasifikacijama ne bi smatrali složenicama, međutim ovi autori utvrđuju stroge kriterijume kojima se potkrepljuje njihova argumentacija (npr. Knittel 2012; Rosenberg 2008).

U narednom delu, ukratko opisujemo korpus koji nam je poslužio kao izvor primera kojima ilustrujemo sintaksička obeležja engleskih i francuskih kanoničkih i nekanoničkih složenica.

$4 \quad$ U citiranom radu se koristi termin ne-centar (Di Sciullo 1997: 20). 


\section{Opis korpusa}

Da bi se stekao jasniji uvid u adekvatnost primera iz korpusa, u ovom delu rada, daje se sažet opis korišćenog korpusa. Ispitivanje engleskih i francuskih kanoničkih i nekanoničkih složenica vršeno je na materijalu iz sledećih šest korpusa koji su označeni kao sledeći inicijalizmi: ODC_PDCW, PE, LE, EUE, FUE i MIT_1_5.

Korpus ODC_PDCW dobijen je ekscerpiranjem složenica iz dva specijalizovana rečnika, i to: Sandra Pyne and Allen Tuck (1996): Oxford Dictionary of Computing, Oxford: Oxford University Press (394 strane) i Robert W. Bly (1983): The Puffin Dictionary of Computer Words, Harmondsworth: Penguin (144 strane). Korpuse PE i LE, Penguin Electronics (PE) i Larousse Électronique (LE), čine: S. Handel (1972): A Dictionary of Electronics. Third Edition, Harmondsworth: Penguin (413 strane) i Jean-François Armand (1966): Dictionnaire de l'électronique, Paris: Librairie Larousse (253 strane),. Korpus EUE i FUE obuhvataju ukupno 100 nasumično odabranih strana. Korpus EUE (= engleski udžbenici elektrotehnike) dobijen je ekscerpiranjem po deset nasumično odabranih strana iz pet engleskih udžbenika elektrotehnike (ukupno 50 strana): Afra J. Zomorodian (2005): Topology for Computing, Cambridge: Cambridge University Press (243 strane), Thomas Cormen, Charles E. Leiserson, Ronald L. Rivest and Clifford Stein (2001): An Introduction to Algorithms, Second Edition, Cambridge, Massachusetts: The MIT Press (985 strana), O. J. Staffans (2005): Well-Posed Linear Systems, Cambridge: Cambridge University Press (776 strana), Hal Schenck (2003): Computational Algebraic Geometry, Cambridge: Cambridge University Press (193 strana), Robert J. Mailloux (2005): Phased Array Antenna Handbook, Second Edition, Boston and London: Artech House (496 strana). Korpus FUE (= francuski udžbenici elektrotehnike) dobijen je ekscerpiranjem po deset nasumično odabranih strana iz pet francuskih udžbenika elektrotehnike (ukupno 50 strana): Jean-Luc Hainaut (2005): Bases de donnés et modèles de calcul: Outils et méthodes pour l'utilisateur - Cours et exercices corrigés, $4^{\text {ème }}$ édition, Paris: Dunod (435 strane), Michel Divay (2004): Algorithmes et structures de donnés génériques, $2^{\mathrm{ème}}$ édition, Paris: Dunod (342 strane), David Tardiveau (2008): ActionScript 3: Programmation séquentielle et orientée objet, Paris: Éditions Eyrolles (397 strana), Tarek Ziadé (2009): Program- 


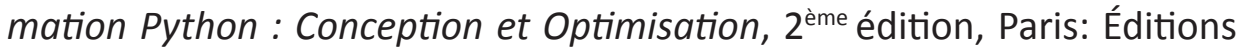
Eyrolles (556 strana), Vincent Granet (2010): Algorithmique et programmation en Java, $3^{\mathrm{m} e}$ édition, Paris: Dunot (395 strana).

Korpus MIT_1_5 obuhvata pet akademskih predavanja održanih u jesen 2005. godine na Fakultetu za elektrotehniku i računarstvo na Masačusetskom Institutu za tehnologiju (skraćeno MIT_1_5). Predavanja su više puta preslušana, transkribovana i anotirana. Korpus MIT_1_5 sadrži ukupno 56 kucane strane, a sadrži ukupno 45273 reči ${ }^{5}$.

Iz korpusa ODC_PDCW ekscerpirano je ukupno 2348 složenica, iz korpusa PE smo ekscerpirali 3715 složenica, a iz LE ukupno 377 složenica, iz korpusa EUE 608 složenica, iz korpusa FUE 549 složenica, a iz korpusa MIT_1_5 ukupno 918 složenica. Iz opisanih korpusa ukupno je ekscerpirano 8515 složenica, i to 7589 engleskih složenica (5737 kanoničkih, 1852 nekanoničke) i 926 francuskih složenica (368 kanoničkih, 558 nekanoničkih).

U narednom delu pogledaćemo relevantne kriterijume za selekciju engleskih i francuskih kanoničkih i nekanoničkih složenica u diskursu elektrotehnike.

\section{Relevantni kriterijumi za selekciju engleskih i francuskih kanoničkih i nekanoničkih složenica}

Leksička jedinica mora da ispuni većinu sledećih kriterijuma kako bi bila definiciono određena kao engleska kanonička složenica ${ }^{6}$. Kriterijum 1 (kriterijum interne strukture): kanonička složenica mora da se sastoji iz dva elementa, odnosno da bude binarna složenica. Kriterijum 2 (ortografski kriterijum): kanonička složenica mora da se piše kao jedan fuzionisani

$5 \quad$ Pored navedenih engleskih i francuskih korpusa, korišćeni su i primeri iz autorove višegodišnje bogate prevodilačke prakse naučnih i stručnih tekstova, kao i iz autorove dugogodišnje nastavne prakse na univerzitetskom nivou.

6 Prilikom utvrđivanja kriterijuma konsultovao sam i literaturu koja predlaže kriterijume za kanoničke engleske složenice, tj. binarne (Bauer 1998: 65-86), ali i kriterijume za razdvajanje fraza, tj. sintagmi od složenica (Bauer 2004: 7-22). Izvesni francuski autori navode četiri kriterijuma za razlikovanje složenica od nominalnih grupa (Silberztein 1993: 405425). Takođe, ovde sam uzeo u obzir kriterijume koje sam već ustanovio za engleske i francuske kanoničke i nekanoničke složenice (Đurić 2016: 25-28). 
ajtem bez belina između grafičke mase. Kriterijum 3 (semantički kriterijum): kanonička složenica mora da ima transparentno značenje, odnosno da bude kompozitna. Kriterijum 4 (morfološki kriterijum): kanonička složenica se u flektivnoj morfologiji mora tretirati kao celina, kao jedna jedinica, odnosno, samo jedan element kanoničke složenice dobija flektivne afikse. Kriterijum 5 (sintaksički kriterijum): kanonička složenica mora da ima sintaksički integritet i fiksiran redosled konstituenata. Kriterijum 6 (prozodijski kriterijum): kanonička složenica mora da ima jedan, primarni akcenat/naglasak. Kriterijum 7 (diskursni kriterijum): kanonička složenica je nezavisna od diskursa, tj. diskursno-nezavisna. Kriterijum 8 (rečnički/ leksikografski kriterijum/kriterijum zastupljenosti u rečniku): kanonička složenica mora da bude zabeležena u specijalizovanom i/ili opštem rečniku. Pogledaćemo sada primere iz mog korpusa koje ćemo provući kroz tabele ispunjenosti kriterijuma.

Najpre ćemo analizirati leksičku jedinicu branchpoint, i videti da li ona ispunjava uslov da se podvede pod kategoriju kanoničkih složenica.

\begin{tabular}{|c|c|}
\hline kriterijum & $\begin{array}{c}\text { zadovoljava (+), } \\
\text { ne zadovoljava ( }- \text { ) }\end{array}$ \\
\hline 1 & + \\
\hline 2 & + \\
\hline 3 & + \\
\hline 4 & + \\
\hline 5 & + \\
\hline 6 & + \\
\hline 7 & + \\
\hline 8 & + \\
\hline
\end{tabular}

Tabela 3.1. Tabela ispunjenosti kriterijuma za složenicu branchpoint.

Leksička jedinica branchpoint ispunjava svih osam kriterijuma. Zaključak: branchpoint je kanonička složenica par excellence.

Pogledaćemo da li i u kojoj meri leksička jedinica electrostatic printer zadovoljava kriterijume za selekciju. 


\begin{tabular}{|c|c|}
\hline Kriterijum & $\begin{array}{c}\text { zadovoljava }(+), \\
\text { ne zadovoljava }(-)\end{array}$ \\
\hline 1 & + \\
\hline 2 & - \\
\hline 3 & + \\
\hline 4 & + \\
\hline 5 & + \\
\hline 6 & - \\
\hline 7 & + \\
\hline 8 & + \\
\hline
\end{tabular}

Tabela 3.2. Tabela ispunjenosti kriterijuma za složenicu electrostatic printer.

Kao što se vidi iz tabele 3.2., nisu zadovoljeni kriterijumi 2 i 6. Međutim, većina kriterijuma $(1,3,4,5,7$ i 8) je zadovoljena. Stoga, leksička jedinica electrostatic printer može da se klasifikuje kao engleska kanonička složenica. Pogledaćemo sada kriterijume za selekciju francuskih kanoničkih složenica.

Leksička jedinica mora da ispuni većinu sledećih kriterijuma kako bi bila definiciono određena kao francuska kanonička složenica. Kriterijum 1 (kriterijum interne strukture): kanonička složenica mora da se sastoji iz dva elementa, odnosno da bude binarna složenica. Kriterijum 2 (ortografski kriterijum): kanonička složenica mora da se piše kao jedan fuzionisani ajtem bez belina između grafičke mase ili eventualno sa crticom između prvog i drugog konstituenta. Kriterijum 3 (semantički kriterijum): kanonička složenica mora da ima transparentno značenje, odnosno da bude kompozitna. Kriterijum 4 (morfološki kriterijum): kanonička složenica se u flektivnoj morfologiji mora tretirati kao celina, kao jedna jedinica, odnosno, samo jedan element kanoničke složenice dobija flektivne afikse. Kriterijum 5 (sintaksički kriterijum): kanonička složenica mora da ima sintaksički integritet i fiksiran redosled konstituenata. Kriterijum 6 (diskursni kriterijum): kanonička složenica je nezavisna od diskursa (tj. diskursno-nezavisna). Kriterijum 7 (rečnički/leksikografski kriterijum): kanonička složenica mora da bude zabeležena u specijalizovanom i/ ili opštem rečniku.

Najpre ćemo analizirati leksiču jedinicu radiotéléphonie, i videti da li ona ispunjava uslov da se podvede pod kategoriju kanoničkih složenica. 


\begin{tabular}{|c|c|}
\hline Kriterijum & $\begin{array}{c}\text { zadovoljava ( + ), } \\
\text { ne zadovoljava ( }-)\end{array}$ \\
\hline 1 & + \\
\hline 2 & + \\
\hline 3 & + \\
\hline 4 & + \\
\hline 5 & + \\
\hline 6 & + \\
\hline 7 & + \\
\hline
\end{tabular}

Tabela 3.3. Tabela ispunjenosti kriterijuma za složenicu radiotéléphonie.

Leksička jedinica radiotéléphonie ispunjava svih sedam kriterijuma. Zaključak: radiotéléphonie je složenica par excellence.

Pogledaćemo da li i u kojoj meri leksička jedinica haut-parleur ispunjava uslove za selekciju.

\begin{tabular}{|c|c|}
\hline Kriterijum & $\begin{array}{c}\text { zadovoljava }(+), \\
\text { ne zadovoljava }(-)\end{array}$ \\
\hline 1 & + \\
\hline 2 & - \\
\hline 3 & - \\
\hline 4 & + \\
\hline 5 & + \\
\hline 6 & + \\
\hline 7 & + \\
\hline
\end{tabular}

Tabela 3.4. Tabela ispunjenosti kriterijuma za složenicu haut-parleur.

Iz tabele 3.4. vidimo da ajtem haut-parleur zadovoljava većinu kriterijuma. Nisu zadovoljeni kriterijumi 2 i 3, ali je većina kriterijuma zadovoljena $(1,4,5,6$ i 7), te ga stoga možemo klasifikovati kao francusku kanoničku složenicu. $U$ delu koji sledi, pogledaćemo kriterijume za selekciju nekanoničkih složenica u engleskom i francuskom.

Da bi se leksički ajtem smatrao nekanoničkom složenicom u engleskom jeziku mora da zadovolji većinu sledećih kriterijuma za selekciju. Kriterijum 1: nekanonička složenica se sastoji od 3, 4, 5 ili više konstituenata. Kriterijum 2: nekanonička složenica se piše kao dva, tri ili više ajtema odvojena belinama i/ili spojenih crticom/crticama. Kriterijum 3: nekanonička složenica nema transparentno značenje, odnosno značenje 
nije kompozitno. Kriterijum 4: nekanonička složenica u flektivnoj morfologiji se ne mora tretirati kao celina (jedna jedinica), može i više od jednog elementa složenice da dobije flektivne afikse. Kriterijum 5: nekanonička složenica može (ali ne mora) da ima izmenjen redosled konstituenata. Kriterijum 6: nekanonička složenica ima više naglasaka i akcenata (primarni, sekundarni, tercijarni). Kriterijum 7: nekanonička složenica je zavisna od diskursa, tj. diskursno-zavisna. Kriterijum 8: nekanonička složenica nije zabeležena u specijalizovanim i/ili opštim rečnicima.

Najpre ću analizirati ispunjenost kriterijuma za leksičku jedinicu transverse-beam travelling wave tube.

\begin{tabular}{|l|l|}
\hline \multicolumn{1}{|c|}{ kriterijum } & \multicolumn{2}{c|}{$\begin{array}{c}\text { zadovoljava }(+), \\
\text { ne zadovoljava }(-)\end{array}$} \\
\hline 1 & + \\
\hline 2 & + \\
\hline 3 & + \\
\hline 4 & - \\
\hline 5 & + \\
\hline 6 & + \\
\hline 7 & + \\
\hline 8 & - \\
\hline
\end{tabular}

Tabela 3.5. Tabela ispunjenosti kriterijuma za složenicu transverse-beam travelling wave tube.

Leksička jedinica transverse-beam travelling wave tube ispunjava šest od osam kriterijuma. Zaključak: transverse-beam travelling wave tube je nekanonička složenica. Pogledaćemo sada kriterijume za francuske nekanoničke složenice.

Da bi se leksički ajtem smatrao nekanoničkom složenicom u francuskom jeziku mora da zadovolji većinu sledećih kriterijuma za selekciju. Kriterijum 1: nekanonička složenica se sastoji od 3, 4, 5 ili više konstituenata. Kriterijum 2: nekanonička složenica se piše kao dva, tri ili više ajtema odvojena belinama i/ili spojenih crticom/crticama. Kriterijum 3: nekanonička složenica nema transparentno značenje, odnosno značenje nije kompozitno. Kriterijum 4: nekanonička složenica u flektivnoj morfologiji se ne mora tretirati kao celina (jedna jedinica), može i više od jednog elementa složenice da dobije flektivne afikse. Kriterijum 
5: nekanonička složenica može (ali ne mora) da ima izmenjen redosled konstituenata. Kriterijum 6: nekanonička složenica je zavisna od diskursa (diskursno-zavisna). Kriterijum 7: nekanonička složenica nije zabeležena u specijalizovanim i/ili opštim rečnicima.

Pogledaćemo tabelu ispunjenosti kriterijuma za leksiču jedinicu courants porteurs en télégraphie.

\begin{tabular}{|c|c|}
\hline kriterijum & $\begin{array}{c}\text { zadovoljava ( + ), } \\
\text { ne zadovoljava ( })\end{array}$ \\
\hline 1 & + \\
\hline 2 & + \\
\hline 3 & - \\
\hline 4 & + \\
\hline 5 & + \\
\hline 6 & + \\
\hline 7 & - \\
\hline \multicolumn{2}{|c|}{ Tabela 3.6. Tabela ispunjenosti kriterijuma za složenicu } \\
courants porteurs en télégraphie.
\end{tabular}

Leksička jedinica courants porteurs en télégraphie ispunjava pet od sedam kriterijuma. Zaključak: courants porteurs en télégraphie je nekanonička složenica.

U narednom delu rada pogledaćemo sintaksička obeležja engleskih i francuskih složenica ilustrovanih primerima iz korpusa.

\section{Analiza sintaksičkih obeležja engleskih i francuskih složenica}

Prema literaturi, postoje barem dva faktora koja komplikuju razmatranje sintaksičkih aspekata složenica (Fabb 1998: 76). Citirani autor konstatuje da se prvi problem ogleda u tome što složenice imaju relativno fiksirano značenje, tako da ih je teško sintaksički modifikovati. Ovo ćemo ilustrovati primerima iz našeg korpusa. Dakle, englesku kanoničku složenicu shadow region ne možemo modifikovati elementom dense, jer bismo generisali rđavo oblikovanu jedinicu *dense shadow region, niti možemo francusku nekanoničku složenicu émetteur ondes courtes modifikovati jedinicom très, jer bismo u tom slučaju dobili rđavo oblikovanu je- 
dinicu *émetteur ondes très courtes. Drugi problem, prema Fabbu, odnosi se na mogućnost da su neke složenice nastale kao rezultat leksikalizacije fraza (Fabb 1998: 76).

U našem istraživanju, najpre smo pogledali mogućnost konstituentske analize, odnosno raščlanjavanje složenica na komponente, tj. konstituente. Zatim smo posmatrali kombinovanje konstituenata složenica, nemogućnost sintaksičke interpolacije, centriranost složenica i sintaksičku rekurzivnost. Sve ovo potkrepljujemo primerima iz engleskog i francuskog diskursa elektrotehnike.

Konstituentska analiza. Prvi problem koji se javlja kod sintaksičke analize složenica jeste raščlanjavanje složenica na konstituente. Naime, raščlanjavanje je ponekada otežano zato što sintaksička struktura može da bude dvosmislena. Na primer, ako uzmemo jednu složenicu iz diskursa elektrotehnika, npr. englesku složenicu band elimination filter iz našeg korpusa, vidimo da se ova složenica može raščlaniti na barem dva načina. Naime, ako podvrgnemo ovu složenicu konstituentskoj analizi, neće biti jasno da li su prvi konstituenti band elimination ili elimination filter. Da bi se doneo izbor između ove dve potencijalne analize mora da se uzme u obzir znanje o svim konstituentima posebno (band, elimination i filter). Sintaksički posmatrano, u kojoj relaciji se nalaze elimination i filter? Da bismo shvatili značenje moramo da identifikujemo implicitne semantičke odnose. Sličnu situaciju nalazimo i u sledećem primeru francuske složenice iz diskursa elektrotehnike, npr. složenicu montage émetteur commun iz našeg korpusa. Ovu složenicu možemo raščlaniti tako što bismo izdvojili kao konstituent montage émetteur, ali ili émetteur commun. Dakle, u slučaju francuske složenice moramo uzeti u obzir znanje o sva tri konstituenta (montage, émetteur i commun).

Kao što smo videli u primerima, složenice se ne mogu uvek sa lakoćom sintaksički raščlaniti, jer nismo sigurni kojim redosledom se primenjuju pravila frazne strukture. Uočavamo da su složenice sintaksički dvosmislene najčešće kada sadrže više od dva konstituenta. Dakle, dvosmislenost kod sintaksičke interpretacije nekanoničkih složenica povećava se povećanjem broja konstituenata. Prema literaturi, strukturni ambigvitet složenica raste eksponencijalno sa njihovom dužinom (Isabelle 1984: 509). Upravo citirani autor navodi složenicu aircraft bobmb bay door actuating cylinders, koja se sastoji od šest konstituenata, a za koju predlaže 
sledeći redosled analize konstituenata: [[aircraft [[bomb bay]] door]] [actuating cylinder]]. Ovim primerom se ilustruje da složenice ispoljavaju sintaksičku dvosmislenost. Pogledaćemo sada kombinovanje konstituenata u okviru složenica.

Kombinovanje konstituenata složenica. Uočili smo da složenice ispoljavaju izvesne obrasce u svom sintaksičkom ponašanju. Dva konstituenta koji se kombinuju u jednu složenicu dalje se mogu proširivati konstituentima i stvarati druge složenice sa većim brojem konstituenata. I engleske i francuske složenice mogu da budu podvrgnute ovoj vrsti rekurzivnosti. Međutim, i kod rekurzivnosti se javlja problem sintaksičkog raščlanjavanja. Naime, pošto smo već videli da su složenice koje imaju više od dva konstituenta sintaksički dvosmislene, tim je sintaksička interpretacija kompleksnija kod nekanoničkih složenica ${ }^{7}$. Srazmerno rastu broja konstituenata proporcionalno raste i broj mogućih sintaksičkih raščlanjavanja. To se može videti na primeru engleskih i francuskih složenica u diskursu elektrotehnike koje opisujemo i objašnjavamo.

Na primer, engleska složenica density function, može se proširiti konstituentom spectral, što rezultira složenicom spectral density function, a dobijena složenica može se proširiti konstituentom power, pa je rezultat složenica power spectral density function. Slično tome, u francuskom diskursu elektrotehnike, na primer, složenica redresseur à bande, može se proširiti konstituentom latérale, što rezultira složenicom redresseur à bande latérale, a dobijena složenica se može proširiti konstituentnom unique, što rezultira složenicom redresseur à bande latérale unique. Prilikom sintaksičkog raščlanjavanja ovih nekanoničkih složenica moramo voditi računa o međuodnosima komponenti. Pogledaćemo sada nemogućnost sintaksičke interpolacije, kao jedno sintaksičko obeležje složenica.

Nemogućnost sintaksičke interpolacije kao osobenost složenica. Jedan od relevantnih sintaksičkih testova za potvrđivanje statusa složenice jeste i taj da se konstituenti složenice ne mogu razdvojiti interpolacijom drugih leksičkih elemenata, a da se ne izgubi značenje složenice. Npr. englesku složenicu blackboard i francusku složenicu pomme de terre ne možemo modifikovati, a da se ne izgubi značenje ovih složenica. Drugim

7 Redosled konstituenata u složenici relevantan je i u srpskom jeziku (Krstev 2008: 116-117), na šta ukazuje i Cvetana Krstev u svojoj studiji, u kojoj se, između ostalog, bavi i integrisanim pristupom za prepoznavanje i generisanje složenica (Krstev 2008: 106-122). 
rečima, ne možemo generisati *black hard board, niti *pomme de bonne terre. Isti slučaj je i sa složenicama u diskursu elektrotehnike. Npr. engleske složenice effective leakage resistance, line bank, root mean square voltage ne mogu se razdvojiti interpolacijom dajući sledeće besmislene nizove: *effective leakage hard resistance, *line pretty bank, *root mean square soft voltage. Identičan je slučaj i sa francuskim složenicama, poput: tension de commande, écran réflecteur, banc de contacts de lignes. Ni ove složenice se ne mogu razdvojiti interpolacijom, a da ne daju besmislene nizove poput: *tension de fleur commande, *écran formica réflecteur, *banc de contacts de vieux lignes. Navedeni primeri ilustruju sintaksičku neprekinutost ili nemogućnost sintaksičkog odvajanja konstituenata složenica umetanjem nekog novog elementa. Svako takvo umetanje, povlači za sobom potpunu promenu značenja složenice, često do neprepoznavanja.

Centriranost složenica u engleskom i francuskom jeziku kao sintaksičko obeležje složenica. Sledeće bitno sintaksičko obeležje, prema literaturi (Bauer and Renouf 2001: 102) jeste položaj centra složenice, odnosno, centriranost. Endocentrične složenice su one koje imaju svoj centar, dok eksocentrične složenice nemaju centar (Napoli 1996: 23). Prema literaturi, centar složenice ima slične osobine kao centar fraze, odnosno predstavlja suštinsko značenje konstituenta i pripada istoj klasi reči (Fabb 1998: 66-67). Prema literaturi, vrsta reči centra i značenje centra određuju značenje i vrstu reči cele složenice (Lardiere 2006: 78). U literaturi se naglašava da je distinkcija između endocentričnih i eksocentričnih složenica nekada stvar interpretacije (Fabb 1998: 67). Takođe, pošto se uglavnom razlikuje položaj centra engleskih složenica od položaja centra francuskih složenica, onda je bitno konstatovati da u engleskom jeziku u većini slučajeva komponenta koja se nalazi skroz desno u okviru engleske složenice identifikuje opštu klasu kojoj značenje cele reči pripada (O'Grady and de Guzman 2006: 154). Pored endocentričnih, postoje i eksocentrične složenice, odnosno, bahuvrihi složenice, kao i koordinativne složenice,odnosno, dvandva složenice (Fabb 1998: 67). Pošto ovom analizom nisu obuhvaćene druge klase, nećemo se ovde posebno baviti daljom klasifikacijom složenica ${ }^{8}$.

8 Detaljnije klasifikacije, terminološki problemi i kriterijumi klasifikacije složenica mogu se naći u literaturi koja u svoj fokus stavlja upravo probleme klasifikacije (vidi: Bisetto and Scalice 2005). Dragocene klasifikacije za engleski jezik struke predlaže i lingvistkinja Jelena Jelić-Vujić u svojim studijama (vidi: Vujić 2004: 155-166; Jelić-Vujić 2007: 175-180). 
U ispitanom korpusu, složenice iz diskursa elektrotehnike su uglavnom endocentrične, odnosno, složenice su hiponimi svog centra. Na primer, engleske kanoničke složenice iz korpusa, kao na primer: cathode bias, commutating capacitor i negative feedback, su sve centrirane ${ }^{9}$, a centri su: bias, capacitor i feedback. Pogledaćemo još nekoliko centriranih engleskih složenica iz korpusa: common mode rejection, equivalent binary digits, instantaneous automatic gain control, glow-discharge cold-cathode tube valve.

Ista situacija je i u francuskom diskursu elektrotehnike. Složenice su uglavnom centrirane. Pogledajmo francuske kanoničke složenice, na primer: champ magnetique, amplification paramétrique i courant alternatif. Sve tri složenice su centrirane, a centri su: champ, amplification i courant. Pogledaćemo još nekoliko centriranih francuskih složenica iz korpusa: changement de fréquence, émetteur de radiodiffusion sonore, échos en modulation de fréquence, multiplication de fréquence.

Pojam centra je relevantan, naročito u pogledu položaja centra koji se razlikuje u engleskom jeziku u odnosu na francuski jezik. Kao što se vidi iz gore navedenih primera, dok je u engleskom centar gotovo uvek na poslednjem mestu sa desne strane, u francuskom je centar skoro sasvim uvek na suprotnoj strani u odnosu na engleske složenice, odnosno nalazi se skroz levo na prvom mestu ${ }^{10}$. Pogledaćemo par primera iz korpusa koji ilustruju ovu pojavu kod engleskih i francuskih složenica u diskursu elektrotehnike.

\begin{tabular}{|c|c|}
\hline engleska složenica & francuska replika \\
\hline field distribution & distribution des champs \\
\hline mutual capacitance & $\underline{\underline{\text { capacitance mutuelle }}}$ \\
\hline magnetic field & $\underline{\underline{\text { champ magnétique }}}$ \\
\hline alternating current & $\underline{\underline{\text { courant }} \text { alternatif }}$ \\
\hline local oscillator & oscillateur local \\
\hline
\end{tabular}

Tabela 3.7. Primeri engleskih složenica iz diskursa elektrotehnike i njihovih francuskih replika.

Posledica činjenice da u endocentričnim složenicama postoji centar dopušta da se kao jedan od testova za utvrđivanje sintaksičkog sta-

9 Sintaksičke centre složenica obeležavamo pomoću dve podvučene linije (npr. element bias u engleskoj složenici cathode bias i i element courant u francuskoj složenici courant alternatif).

10 Međutim, lingvistkinja Marija Rozenberg nas informiše i o primerima francuskih složenica u kojima se centar može nalaziti i skroz desno (Rosenberg 2007: 345). 
tusa složenica koristi test brisanja centra složenice i to u koordiniranoj sintaksičkoj strukturi koja se sastoji od dve ili više složenice koje dele isti centar. Najpre ćemo primeniti ovaj sintaksički test na engleske složenice u diskursu elektrotehnike, a zatim i na francuske složenice.

Primenićemo ovaj sintaksički test na sledeće parove engleskih složenica: 1. field intensity i magnetic intensity, 2. relational operator i logic operator.

* field intensity and magnetic

* relational__and logic operator

Ovim sintaksičkim testom dokazuje se da je neki ajtem složenica. Sledstveno tome, primenom testa brisanja centra $u$ koordiniranim sintaksičkim strukturama dokazali smo da su field intensity, magnetic intensity, relational operator i logic operator složenice par excellence. Pogledaćemo primenu ovog testa na francuske složenice u diskursu elektrotehnike, i to na primeru sledećih parova: 1. circuit integré i circuit logique, 2. bande latérale i bande magnétique.

*circuit integré et logique

*__latérale et bande magnétique

Primenom ovog sintaksičkog testa na francuske složenice u diskursu elektrotehnike vidimo da centar ne može da se briše, što je dovoljan dokaz da su ajtemi circuit integré, circuit logique, bande latérale i bande magnétique složenice par excellence.

Sledeće sintaksičko obeležje složenica odnosi se na nemogućnost zamene centra nekim drugim ajtemima. Složenice u diskursu elektrotehnike (a pretpostavljam i u drugim diskursima) jesu anaforička ostrva. Engleske složenice ne dozvoljavaju zamenu centra zamenicom one, odnosno, francuske složenice ne dozvoljavaju zamenu centra zamenicom un. Shodno tome, ako uzmemo u obzir engleske složenice iz diskursa elektrotehnike: jedan par sa strukturom ", $\mathrm{N}+\mathrm{N}$ “ (injection grid, screen grid) $\mathrm{i}$ jedan par sa strukturom „Adj+N $\mathrm{N}_{\text {PLUR }}$ " (distributed constants, physical constants), a onda i francuske složenice iz diskursa elektrotehnike: jedan par sa strukturom "N+Adj" (courant monophasé, courant alternatif) i jedan par sa strukturom " $\mathrm{N}_{\mathrm{PLUR}}+\mathrm{Adj}^{\prime \prime}$ (ondes courtes, ondes métriques), i ukoliko pokušamo da u navedenim parovima centar zamenimo zamenicom one (u engleskim primerima), tj zamenicom un (u francuskim primerima), generisaćemo nizove koji su rđavo oblikovani: 
*injection greed and screen one

* distributed constants and physical ones

*courant monophasé et un alternatif

*ondes courtes et uns métriques

Kao što se vidi iz priloženih primera, to su rđavo oblikovani sledovi, a ovim primerima ilustrujemo sintaksičko obeležje složenica da engleske složenice ne dozvoljavaju zamenu centra engleskom zamenicom one, a francuske složenice ne dozvoljavaju zamenu centra francuskom zamenicom un. U nastavku ćemo pogledati sintaksičku rekurzivnost kao dominantno obeležje složenica u diskursu elektrotehnike.

Sintaksička rekurzivnost kao dominantno obeležje složenica. Čini nam se da je u diskursu elektrotehnike najistaknutije obeležje tog diskursa činjenica da se javljaju složenice koje po prethodno navedenim sintaksičkim testovima spadaju u tu pojavu, a koje mogu da se povećavaju u zavidnom broju.

Ilustrovaćemo to primerima sintaksičkih konstrukta koje možemo da uvrstimo u nekanoničke složenice u diskursu elektrotehnike jer podležu gore navedenim testovima, a u svom centru sadrže konstituent koji je zapravo leksema sa bitnim semantičkim sadržajem za dotični diskurs.

Pogledaćemo uzorak engleskih složenica čiji je centar leksema LASER: bidirectional laser, bistable laser, black-body laser, black-body-pumped laser, Bragg laser, Brewster-angled laser, bromine vapor laser, bulk-ionized laser, cadmium-selenide laser, cadmium sulfide laser, cadmium vapor laser, calcium vapor laser, carbon dioxide laser, carbon monoxide laser, carbon vapor laser, carrier-injection laser, cascade laser,cataphoresis pumping laser, cavity laser, ceramic laser, chain-reaction laser, chemical transfer laser, chemically-activated elimination laser, chemically excited laser, chemically excited molecular laser, chemically pumped laser, chemically pumped molecular laser, circulated-liquid laser, closed-cycle laser, coaxial laser, coaxial-flow laser, coaxial pump laser, communication laser, composite-rod laser, Compton laser, condensed-phase laser, confined-phase laser, confocal laser, continuous laser, continuous-wave laser, continuous-wave semiconductor laser, continuously operated ruby laser, continuosly-operating laser, continuously-operating iodine laser, continuously-operating liquid laser, continuously-operating organic liquid laser, continuously-operating solid laser, continuously-pumped laser, convec- 
tively-cooled laser, copper iodide laser, copper vapor laser, coumarin laser, cross-beam laser, cross-discharge laser, cross-field laser, cross-pumped laser, cryogenic laser, crystal laser, crystalline laserdc-excited laser, deflection laser, deuterium fluoride laser, deuterium-fluoride chemical laser, diatomic laser, dielectric gas laser, dielectric solid-state laser, diffraction limited laser, diffused laser, diffusion-cooled laser, dimer laser, diode laser, diode laser pumped solid-state laser, dual-cavity laser, dual polarization laser, dye laser, dye-doped polymethylmethacrylate laser, dynamic laser.

Sada ćemo pogledati uzorak francuskih složenica čiji je centar leksema CIRCUIT: circuit bihpasé, circuit blindé, circuit bloqueur, circuit bouchon, circuit bouclé, circuit canonique, circuit cathodique, circuit combinant, circuit combiné, circuit combiné double, circuit combiné quadruple, circuit combiné simple, circuit simple, circuit comparateur, circuit complexe, circuit contre-distorsif, circuit correctif, circuit couplé, circuit d'abonnement, circuit d'absorption, circuit d'accord, circuit d'adaptation, circuit d'affaiblissement, circuit d'alarme, circuit d'alimentation, circuit d'alumage, circuit d'amortissement, circuit d'annoce, circuit d'anode, circuit d'antenne, circuit d'appel, circuit d'arrivée, circuit d'atténuation, circuit de balayage, circuit de base de temps, circuit de Boole, circuit de charge, circuit de charge équivalent, circuit de chauffage, circuit de commande, circuit de commutation, circuit de compensation, circuit de comptage, circuit de conférence, circuit de contrôle, circuit de conversation, circuit de conversation pour une transmission radiophonique, circuit de conversion de phase, circuit de correction, circuit de coupage, circuit de courant, circuit de courant d'appel, circuit de courants de Foucault, circuit de déblocage, circuit de décharge, circuit de découplage, circuit de demande, circuit de démarrage, circuit de dérivation, circuit de détection de défauts, circuit de différentiation.

Ovakve složenice, kao što su upravo navedene, podsećaju na fraze, ali one to nisu, jer se u rečenici ponašaju kao samostalne reči (Radford et al. 1999: 171). Broj konstituenata nije ograničen i proces građenja rekurzijom može da se odvija ad infinitum, pošto ne postoji teorijski limit za broj konsituenata koji ulaze u složenicu (Radford et al. 1999: 172), a složenica može da bude i osnova za dalju kompoziciju (Lardiere 2006: 77). Kao što se vidi iz ovih primera iz engleskog i francuskog jezika u većini slučajeva radi se o složenicama sa dva ili tri konstituenta, ali ima i četvorokonstituentskih 
složenica. U nekim slučajevima, čini se, da postoji sinonimija između složenica, a da se više konstituenata stvara kada je potrebno precizirati značenje složenice. Na primer, deuterium fluoride laser i deuterium fluoride chemical laser čini se da nose isto značenje, ali u drugom slučaju imamo dodato chemical. U drugim slučajevima čini se da se stvaraju grupe leksema složenica koje su međusobno različite samo po jednom konstituentu (npr. dielectric gas laser, dielectric solid state laser) te da se unutar ovih lista složenica mogu uspostaviti višestruki semantički odnosi.

U svakom slučaju, smatramo da bez obzira na dosta visok stepen kreativnosti u kombinovanju konstituenata unutar složenica zapravo odgovara potrebi naučnog diskursa u kome se nastoji stvoriti termin koji će što preciznije odrediti i označiti određenu pojavu.

Sa lingvističke tačke, ovakvo ispoljavanje složenica u stručnom diskursu možda ukazuje na opštu pojavu da se stvaranje složenica uvek na neki način približava kombinovanju konstituenata u odgovarajući sintaksički konstrukt i u opštem jeziku, pa otuda nailazimo na primere u kojima se složenicama proglašavaju sintagmatski skupovi koji imaju semantički referentni odnos prema pojavi u svetu, a koji po našem tradicionalnom osećanju šta je složenica često deluju neuobičajeno barem kada su u pitanju engleski jezik i francuski jezik.

\section{Diskusija i zaključne napomene}

Nakon što smo usvojili radne definicije i polazna određenja složenica na početku ovog rada, izvršili smo klasifikaciju na osnovu relevantnih kriterijuma za selekciju engleskih i francuskih kanoničkih i nekanoničkih složenica. Na osnovu uvida u relevantnu literaturu, utvrdili smo osam kriterijuma za selekciju engleskih kanoničkih složenica, sedam kriterijuma za selekciju francuskih kanoničkih složenica, osam kriterijuma za selekciju engleskih nekanoničkih složenica i sedam kriterijuma za selekciju francuskih nekanoničkih složenica. Složenice iz korpusa smo provukli kroz matricu kriterijuma i utvrdili da se sve složenice iz našeg korpusa mogu klasifikovati kao kanoničke i nekanoničke složenice. Zatim smo izvršili analizu sintaksičkih obeležja engleskih i francuskih složenica.

Iz sintaksičke perspektive javlja se mogućnost konstituentske analize, a na osnovu naših nalaza prilikom analize primera iz korpusa ukazali 
smo na to da se engleske i francuske složenice ne mogu uvek sa lakoćom sintaksički raščlaniti. $U$ delu posvećenom kombinovanju konstituenata složenica utvrdili smo da su složenice koje imaju više od dva konstituenta sintaksički dvosmislene. Takođe, na osnovu analize primera engleskih i francuskih složenica iz korpusa koje smo opisali i objasnili, utvrđeno je da srazmerno rastu broja konstituenata proporcionalno raste i broj mogućih sintaksičkih raščlanjavanja.

Pažnja je posvećena i nemogućnosti sintaksičke interpolacije. Ilustrovali smo primerima iz korpusa sintaksičku neprekinutost, odnosno, nemogućnost sintaksičkog odvajanja konstituenata engleskih i francuskih složenica umetanjem nekog novog elementa, pošto smo serijom testova našli da svako takvo umetanje povlači za sobom potpunu izmenu značenja složenice, često do neprepoznavanja. Opisali smo i objasnili centriranost složenica u engleskom i francuskom jeziku kao sintaksičko obeležje složenica. U ovom delu smo primenili i test brisanja centra u koordiniranim sintaksičkim strukturama kao dokaz statusa složenice.

Prilikom analize sintaksičke rekurzivnosti kao dominantnog obeležja engleskih i francuskih složenica u diskursu elektrotehnike utvrdili smo da ekscerpirani primeri iz korpusa sadrže dva ili tri konstituenta, ali ima i četvorokonstituentskih složenica. U nekim slučajevima, čini se, da postoji sinonimija između složenica, a da se više konstituenata stvara kada je potrebno precizirati značenje složenice. Na primer, čini se da neke složenice nose isto značenje, ali u drugom slučaju imamo dodat konstituent koji unosi promenu značenja. $U$ drugim slučajevima čini se da se stvaraju grupe leksema složenica koje su međusobno različite samo po jednom konstituentu te da se unutar ovih lista složenica mogu uspostaviti višestruki semantički odnosi.

U svakom slučaju, smatramo da bez obzira na dosta visok stepen kreativnosti u kombinovanju konstituenata unutar složenica zapravo odgovara potrebi elektrotehničkog diskursa u kome se nastoji stvoriti termin koji će što preciznije odrediti i označiti određenu pojavu. Sa lingvističke tačke, ovakvo ispoljavanje složenica u naučnom i stručnom diskursu, kao što je diskurs elektrotehnike, možda ukazuje na opštu pojavu da se stvaranje složenica uvek na neki način približava kombinovanju konstituenata u odgovarajući sintaksički konstrukt i u opštem jeziku, pa otuda nailazimo na primere u kojima se engleskim i francuskim složenicama 
proglašavaju sintagmatski skupovi koji imaju semantički referentni odnos prema pojavi u svetu, a koji po našem tradicionalnom osećanju šta je složenica često deluju neuobičajeno barem kad su u pitanju engleski jezik ili francuski jezik.

\section{Literatura:}

Aitchison, James. Cassell's Dictionary of English Grammar. London: Cassell \& Co, 2001. Print.

Bartolić, Ljerka. „Imenske složenice u tehničkom engleskom jeziku." STRANI JEZICI, VII, 1979, 1-2, (1979): 47-58. Print.

Bauer, Laurie. "When is a sequence of two nouns a compound in English?." English Language and Linguistics, Volume 2, Issue 1, (1998): 65-86. Print.

Bauer, Laurie. "Adjectives, compounds and words." Nordic Journal of English Studies, Vol. 3, No. 1, (2004): 7-22. Print.

Bauer, Laurie and Antoinette Renouf. "A corpus-based study of compounding in English." Journal of English Linguistics, Volume 29, Number 2, (2001): 100-123. Print.

Bisetto, Antonietta and Sergio Scalise. "The classification of compounds." Lingue e linguaggio, IV, 2, (2005): 319-332. Print.

Di Sciullo, Anna-Maria. "Economy of X $\mathrm{X}$ XP derivations." Proceedings of the First Mediterranean Conference on Morphology, Volume 1: Allomorphy, Compounding, Inflection. Ed. Geert Booij, Angela Ralli and Sergio Scalise. Mytilene: University of Patras, 1997. 120-131. Print.

Đurić, Miloš D. „Kanoničke i nekanoničke složenice u engleskom i francuskom jeziku.“ PREVODILAC, XXXIII, 76, 3-4, (2016): 22-39. Print.

Fabb, Nigel. "Compounding." Handbook of Morphology. Ed. Andrew Spencer and Arnold M. Zwicky. Oxford: Blackwell, 1998. 66-83. Print.

Fišer-Popović, Ana. „O nekim semantičkim osobinama imeničkih složenica u engleskom jeziku tehničkih nauka." Strani jezik struke u teoriji i praksi. Ed. Nadežda Vinaver. Beograd: Udruženje univerzitetskih nastavnika i drugih naučnih radnika Srbije i Osnovna organizacija nastavnika stranih jezika na nefilološkim fakultetima i višim školama, 1981. 160-167. Print.

Gross, Gaston. "Définition des mots composés dans un lexique-grammaire." Langue française, $n^{\circ} 87$, Dictionnaires électroniques du français, sous la direction de Blandine Courtois et Max Silberztein, (1990): 84-90. Print.

Gross, Maurice. "The representation of compound words. Lexicon-grammar." Proceedings of the $11^{\text {th }}$ International Conference on Computational Linguistics. Ed. Makoto Nagao. Bonn: Institut für angewandte Kommunikations- und Sprachforschung e. V., 1986. 1-6. Print.

Isabelle, Pierre. "Another look at nominal compounds." Proceedings of the $10^{\text {th }}$ International Conference on Computational Linguistics and $22^{\text {nd }}$ Annual Meeting of the 
Association for Computational Linguistics. Stanford, California: Stanford University Press, 1984. 509-516. Print.

Jelić-Vujić, Jelena. „Složenice kao termini kompjuterskog registra.“ Language for Specific Purposes. Ed. Igor Lakić and Nataša Kostić. Podgorica: Institute of Foreign Languages, University of Montenegro, 2007. 175-180. Print.

Knittel, Marie Laurence. "Détermination et modification dans les expressions $\mathrm{N}$ à $\mathrm{N}$ en français." Journal of French Language Studies Volume 22, Issue 2, (2012): 165187. Print.

Korać, Gordana. Predikatske priloške odredbe u savremenom engleskom jeziku. Beograd: Filološki fakultet, Univerzitet u Beogradu, 1988. Print.

Krstev, Cvetana. Processing of Serbian: Automata, Texts and Electronic Dictionaries. Belgrade: Faculty of Philology, University of Belgrade, 2008. Print.

Lakić, Igor. Analiza žanra: Diskurs jezika struke. Podgorica: Institut za strane jezike, Univerzitet Crne Gore, 1999. Print.

Lardiere, Donna. "Words and their parts." An Introduction to Language and Linguistics. Ed. Ralph W. Fasold and Jeff Connor-Linton. Cambridge: Cambridge University Press, 2006. 55-96. Print.

Marcellesi, Jean-Baptiste. "Le lexique." La linguistique. Ed. Pierre Caussat et al. Paris: Larousse, 1977. 187-197. Print.

Napoli, Donna Jo. Linguistics - An Introduction. New York and Oxford: Oxford University Press, 1996. Print.

O’Grady, William and Videa P. de Guzman. "Morphology: The Analysis of Word Structure." Contemporary Linguistics - An Introduction. Ed. William O'Grady, Michael Dobrovolsky and Francis Katamba. London: Longman, 2006. 132-180. Print.

Radford, Andrew et al. Linguistics - An Introduction. Cambridge: Cambridge University Press, 1999. Print.

Rosenberg, Maria. "Classification, headedness and pluralization: Corpus evidence from French compounds." Acta Linguistica Hungarica, Volume 54, Number 3, (2007): 341-360. Print.

Rosenberg, Maria. La formation agentive en français: Les composés $[V N / A / A d v / P]_{N / A}$ et les dérivés $V$-ant, $V$-eur et $V$-oir(e). Cahiers de la Recherche 37. Stockholm: University of Stockholm, 2008.

Silberztein, Max. "Le dictionnaire électronique des mots composés." Langue française, n87, Dictionnaires électroniques du français, sous la direction de Blandine Courtois et Max Silberztein, (1990): 71-83. Print.

Silberztein, Max. "Les groupes nominaux productifs et les noms composés lexicalisés." Lingvisticæ Investigationes, Volume 17, Issue 2, (1993): 405-425. Print.

Smith, Neil and Deirdre Wilson. Modern Linguistics: The Results of Chomsky's Revolution. Hardmondsworth: Penguin, 1979. Print.

Vujić, Jelena. „Morfološka analiza bipolarnih imeničkih složenica u kompjuterskom registru." Lingvističke analize: Zbornik u čast 25 godina Instituta za strane jezike u Podgorici. Ed. Slavica Perović \& Vesna Bulatović. Podgorica: Institut za strane jezike, 2004. 155-156. Print. 
Miloš D. Đurić

University of Belgrade

Faculty of Electrical Engineering

SYNTACTIC ASPECTS OF CANONICAI

AND NON-CANONICAL COMPOUNDS

IN ENGLISH AND FRENCH ELECTRICAL

ENGINEERING DISCOURSES

\section{Summary}

This paper sets out to explore syntactic aspects of English and French compounds in order to get a better understanding of their role in electrical engineering discourse. The observations that I make in this paper are based on the data that have been collected from both oral and written media in English and French. The paper is organised in the following manner. The first part focuses on general definitions of compounds. The second part presents the corpus that served as input to my subsequent explanation, argumentation and conclusions. In the third part, I propose specific criteria that must obtain for a linguistic item to count as a canonical or non-canonical compound in English and French electrical engineering discourses. The fourth part deals with diverse syntactic features of English and French compounds, which are then checked against the corpus material. The fifth part summarises my findings.

Key Words: Canonical Compounds, Non-Canonical Compounds, Syntactic Features, English Compounds, French Compounds, Electrical Engineering Discourse. 